

\section{OS INVENTÁRIOS DE JARDINS HISTÓRICOS E A CONSTRUÇÃO DAS FICHAS DE CADASTRO COMPLEMENTAR PARA O SISTEMA INTEGRADO DE CONHECIMENTO E GESTÃO - SICG}

\author{
Mônica de Medeiros Mongelli \\ Arquiteta e Coordenadora no Departamento do Patrimônio Material e Fiscalização - Depam \\ Instituto do Patrimônio Histórico e Artístico Nacional - Iphan, Ministério da Cultura - Governo \\ Federal do Brasil
}

\author{
Andrey Schlee \\ Diretor do Departamento de Patrimônio Material do IPHAN
}

\section{RESUMO}

Os jardins históricos são um tipo de bem paisagístico diferenciado dos demais bens materiais que integram o patrimônio histórico e artístico; por suas particularidades, requerem tratamento específico. O que se apresenta nesse trabalho é uma maneira de caracterizalos, descrevê-los por meio de fichas de inventário constituídas para o Sistema Integrado de Conhecimento e Gestão - SICG, planejado pelo Instituto do Patrimônio Histórico e Artístico Nacional - IPHAN / Ministério da Cultura - Governo Federal do Brasil. Trata-se do desenvolvimento de uma ferramenta de uso federativo, a qual permite a formação de uma rede georreferenciada de informações sobre os bens culturais brasileiros, com o objetivo de promover sua preservação.

Desde 2006, o IPHAN vem desenvolvendo a metodologia SICG. Num primeiro momento, ela foi aplicada por meio de fichas de inventário elaboradas em Word e Excel, para estudos e processos de gestão do patrimônio cultural. A partir de 2011, uma plataforma nova de software livre para os bens culturais começou a ser desenvolvida; em 2012, foi preparada a ficha específica de Cadastro Complementar para Jardins Históricos, que será aqui apresentada.
Palavras chave: jardins históricos, inventário, patrimônio cultural, SICG 


\section{ID_PESQUISAS}

\section{RESUMEN}

Los jardines históricos son un tipo de patrimonio paisajistico que requieren tratamiento específico, por sus peculiaridades, entre los demás bienes materiales que componen el patrimonio histórico y artístico. Lo que se presenta en este trabajo es una manera de caracterizarlos, describirlos, a través de formas de inventario establecidas como parte del Sistema Integrado de Conocimiento y Gestión - SICG, planeado por el Instituto del Patrimonio Histórico y Artístico Nacional - IPHAN / Ministerio de Cultura - Gobierno de Brasil. Esta es una herramienta de uso federal siendo desarrollada con la finalidad de crear una red de información georeferenciada, promoción y preservación del patrimonio cultural brasileño.

EI IPHAN viene desarrollando la metodología SICG desde 2006. Su primer uso fue a través de formularios hechos en los programas Word y Excel, para el estudio y la gestión del patrimonio cultural. Desde 2011, una plataforma nueva de software libre para los bienes culturales comenzó a ser desarrollada y, en 2012, fue preparado el formulario especifico para el registro complementario de los Jardines Históricos, tema que se presenta aquí.

Palabras clave: jardines históricos, inventario, patrimonio cultural, SICG

\section{ABSTRACT}

The historic gardens are a type of landscape asset that require specific treatment due to its peculiarities as part of the historic and artistic heritage. This paper presents a way to characterize and describe them, through inventory forms established for the Integrated System for Knowledge and Management - SICG. This is a federal tool being developed by the National Historic and Artistic Heritage Institute - IPHAN I Ministry of Culture - Brazil Government, in order to create a georeferenced network for information, promotion and preservation of the brazilian cultural heritage.

Since 2006, IPHAN has been developing the SICG methodology. Initially, it was applied through forms drawn up in Word and Excel programs, for the purpose of studying and managing the cultural heritage. From 2011 on, a free platform software for the cultural heritage began to be developed and, in 2012, the complementary registration form for Historic Gardens was finally elaborated and will be presented here.

Keywords: historic gardens, inventory, cultural heritage, SICG 


\section{SISTEMAINTEGRADO DE CONHECIMENTO E GESTÃO-SICG EA INFORMATIZAÇÃO DOS INVENTÁRIOS NO IPHAN}

O Sistema Integrado de Conhecimento e Gestão - SICG consiste em uma base de dados informatizada sobre o patrimônio cultural, implicando a geração e manipulação de dados sobre os bens, assim como sua transmissão e difusão para a sociedade.

A metodologia envolve a coleta de informações georreferenciadas sobre os bens culturais, vincula o conhecimento à gestão do patrimônio, de modo automatizado, em escala nacional. Um dos principais ganhos possibilitados pela construção desse sistema foi a revisão da dimensão estratégica dos inventários. Até então, o IPHAN possuía alguns inventários em bases de dados distintas e seguindo metodologias diferentes. Eles não estavam integrados: havia um para caracterização de bens arquitetônicos, outro para a configuração dos espaços urbanos, outro para bens móveis e integrados, e assim por diante, sendo que ao final os produtos em sua maioria ficavam disponíveis apenas em papel, mostrando-se estanques e pouco acessíveis à sociedade. Outra questão era que alguns desses inventários exigiam detalhamento aprofundado de informações técnicas e nem tudo confluía para um rebatimento prático frente às necessidades gerenciais ou ao trabalho cotidiano do Iphan, no que se refere às avaliações, monitoramento e gestão dos bens tombados. As pesquisas, portanto, não se mostravam exatamente aplicadas, pois se estendiam além do necessário, gerando produtos finais por vezes excessivamente detalhados e pouco direcionados à missão institucional e às formas de atuação da autarquia.

Com base nessa avaliação, foi proposta a revisão da metodologia de inventários, objetivando a vinculação do conhecimento à gestão, e que o SICG fosse um sistema ágil, de fácil aplicabilidade, capaz de atender à premissa da democratização das informações e acesso ampliado aos dados sobre os bens culturais por parte da sociedade. O ideal buscado para os inventários foi, então, sistematizar o conhecimento e submeter os procedimentos de levantamento e geração de informações à proteção do patrimônio, contribuindo para a necessária avaliação das ações implementadas pelo IPHAN e seus parceiros.

Por isso, para além do Módulo de Conhecimento, o SICG previu os Módulos de Gestão e de Cadastro, todos complementares e inter-relacionados, adaptáveis à identificação do bem patrimonial de qualquer natureza e categoria (bem móvel, bem imóvel, bem paisagístico, sítio arqueológico, conjunto urbano etc.). A metodologia permitiu, por exemplo, dar suporte 
à construção de normas de preservação para os sítios urbanos tombados, como uma estratégia de desenvolvimento socioeconômico local. Ou seja: parte dos dados necessários à gestão dos sítios urbanos tombados já estava contemplada entre os itens de caracterização do bem, inter-relacionando os Módulos de Conhecimento, Cadastro e Gestão.

Esses três módulos do SICG foram pensados para permitir uma abordagem ampliada do patrimônio cultural, partindo do geral para o específico, com recortes temáticos e territoriais definidos. Enquanto o primeiro recorte especifica o tema ou a ótica sob a qual se pretende abordar os bens a serem conhecidos, o segundo delineia a região do estudo.

Trata-se de mais uma razão estratégica, pois se pretendeu o cruzamento e a ressignificação das informações sobre o patrimônio no território nacional, possibilitando que as ações de identificação fossem além dos bens individuais; contemplando os sítios; permitindo a visualização de outros bens semelhantes; e atingindo níveis de análise regionais e até nacional. Por esses motivos, tais inventários foram também chamados "inventários de varredura", objetivando o conhecimento expedito do universo patrimonial dos bens culturais, e propiciando o aprofundamento dos estudos nos casos julgados necessários.

Assim, buscou-se inventariar e cadastrar o estoque patrimonial existente, bem como expandir esse estoque atendendo às diversificações temáticas e à dimensão continental do território nacional; com isso, conhecer, levantar, sistematizar, instrumentalizar e subsidiar ações de gestão e preservação do patrimônio cultural, sob perspectiva de ampliação das relações institucionais e constituição de ações em parceria. Estimulou-se, portanto, a exploração, uso e apropriação dos dados gerados pelos inventários, como instrumentos de gestão e monitoramento do patrimônio.

\section{OS MÓDULOS DO SICG}

Para melhor entendimento do Sistema SICG, comentaremos brevemente sua estrutura nos três Módulos: de Conhecimento, Cadastro e Gestão.

O Módulo de Conhecimento reúne informações que contextualizam, na história e no território, os bens culturais, ou seja, organiza as informações provenientes de universos culturais territoriais ou temáticos. É composto pelas fichas: M101 - Contextualização Geral e M102 - Contexto Imediato; e propõe a visada desde o recorte territorial mais amplo até o mais específico, visando a apresentar um panorama sobre um conjunto de bens relacionados ao universo cultural pesquisado. 
Esse módulo possui campos destinados à coleta e análise de informações cartográficas e de localização dos sítios; informações históricas e de contextualização do objeto; iconografia; observações sobre os contextos geográficos e ambientais; sobre a morfologia e tipologia dos sítios; análises socioeconômicas; informações sobre uso e apropriação dos espaços, entre outros.

Nos casos de inventário sobre bens já tombados pelo IPHAN, orienta-se a inserção no SICG de informações sobre o processo de tombamento, incluindo os valores culturais destacados pelos pareceres técnicos e os do Conselho Consultivo do Patrimônio Cultural, instância que subsidia a decisão final sobre o tombamento ou não do bem.

Já o Módulo de Cadastro reúne um conjunto de fichas aplicáveis à caracterização de bens individuais, com interesse cultural potencial ou já legalmente protegidos. Contém uma ficha padrão, denominada M301 - Cadastro Geral, ou "Cadastro Básico", aplicável a todas as naturezas de bens e categorias do patrimônio material. Permite, portanto, a identificação de cada objeto patrimonial e o arrolamento de suas características essenciais, além de fornecer um número específico para identificação do bem, comparável a sua "cédula de identidade". A partir dessa etapa de cadastramento básico, é possível aprofundar os conhecimentos sobre os bens através da seleção de outras fichas especializadas, por exemplo, sobre arquitetura externa e interna dos imóveis, bens móveis e integrados, conjuntos rurais, jardins históricos etc. As fichas especializadas, chamadas fichas de "Cadastro Complementar", são indicadas para bens com especial interesse de gestão ou proteção, ou para objetos patrimoniais destacáveis, geralmente por sua exemplaridade ou excepcionalidade.

Assim como nos outros módulos, as fichas do Módulo de Cadastro devem ser atualizadas periodicamente e formam a base de dados para a gestão dos bens protegidos. Porém, essa atualização mantém o histórico das intervenções e da evolução do bem - especialmente do ponto de vista de seu estado de conservação e preservação.

É nessa ficha M301 - Cadastro Geral, ou "Cadastro Básico", portanto, que se compõe o código identificador do bem, a ser reproduzido em todas as fichas especializadas, caso preenchidas. Tal código possibilita o rastreamento do bem em outras fichas, bancos de dados ou sistemas, e é também utilizado para as atividades rotineiras de Fiscalização dos bens tombados. Nesse sentido, dois diferentes sistemas tecnológicos foram planejados e desenvolvidos no IPHAN: o SICG e o Sistema Informatizado de Fiscalização - fiscalis. 
Este foi constituído de dois módulos: web e móvel, com o intuito de agilizar o planejamento, gerenciamento e execução das fiscalizações dos bens acautelados ou com interesse cultural potencial. Enquanto o módulo "web" tem como função o gerenciamento, planejamento e monitoramento da atividade de fiscalização, o módulo "móvel" permite que a atividade de campo utilize tablets e impressoras portáteis. Com isso, o fiscalis permite o processamento, armazenamento, planejamento, controle e segurança eletrônica da informação, reduzindo, inclusive, o tempo de instrução e tramitação dos processos de autorização de intervenções em bens tombados e das próprias atividades rotineiras da fiscalização.

Em resumo, o desenvolvimento dos diferentes sistemas, integrados, baseia-se nos programas computacionais para Geoprocessamento e adota o Sistema de Informação Geográfica-SIG, que coleta os dados com suas respectivas localizações (sistema de coordenadas). Conforme informa o "Manual de Aplicação do Sistema Integrado de Conhecimento e Gestão - SICG" (IPHAN, 2009):

Atualmente os programas computacionais para Geoprocessamento, conhecidos como Sistemas de Informação Geográfica (SIG) ou Sistema de Informação Geo-referenciada, (em inglês: Geographic Information System - GIS), possibilitam a realização de interações complexas entre elementos geométricos e bancos de dados geo-referenciados, automatizando a produção de produtos cartográficos.

Dessa forma, são ações rotineiras em um SIG a inserção, integração, combinação de elementos espaciais e seus atributos, através de algoritmos de modelagem e análise, bem como a consulta, recuperação e visualização do conteúdo da base de dados geográficos.

No caso do IPHAN, o SIG deve ser visto como uma ferramenta de planejamento e gestão do patrimônio, instrumentalizando a conservação, o monitoramento e o feedback necessários às políticas públicas e aos objetivos do próprio sistema de conservação.

O Módulo de Cadastro é ainda composto pela ficha M300 - Planilha Síntese, que consiste em uma listagem resumida contendo dados de identificação, localização e informações relevantes para a gestão do bem (estado de conservação, estado de preservação, proteção existente e proteção proposta, propriedade, informações cadastrais, data de preenchimento e a fonte das informações). Essa planilha faz a correlação de todos os bens cadastrados e ordena os códigos identificadores. 
Finalmente, o Módulo de Gestão do SICG estimula estratégias de gestão e valorização dos bens culturais cadastrados. Também articula o processo de conhecimento e o de cadastramento dos bens, valendo-se das informações mais relevantes. O método pressupõe uma atitude propositiva incorporada às análises, visando a objetivar e agilizar os processos de gestão, incluindo: normatização de áreas protegidas; ações de qualificação de áreas urbanas e rurais; produção de diagnósticos de conservação; elaboração de relatórios fotográficos; subsídios para as rotinas de fiscalização em bens e sítios tombados. Nesse módulo, as fichas estão voltadas para a coleta de informações necessárias à gestão do bem, auxiliam nas rotinas de fiscalização, na construção de normatizações e planos de preservação, ou nos diagnósticos urbanos para qualificação dos centros históricos.

Entre outras fichas, o módulo é integrado pela M201 - Pré-Setorização; M202- Caracterização dos Setores; M203 - Averiguação e Proposição Local; M204 - Diagnóstico de Áreas Urbanas - Lote; M205 - Diagnóstico de Áreas Urbanas - Quadra; M206 - Diagnóstico do Estado de Conservação; M207 - Relatório Fotográfico; M208 a M209 - Fiscalização; Ficha M210 - Laudo de Constatação. Nesse artigo, o conteúdo do módulo não será aprofundado; terão maior ênfase o Módulo de Cadastro e a construção da ficha complementar de Jardins Históricos.

\section{CADASTRAMENTO DE JARDINS HISTÓRICOS}

Em relação ao processo de identificação e caracterização dos Jardins Históricos, a primeira decisão para a taxonomia no vocabulário controlado do SICG foi quanto à classificação desses bens como "Bens Paisagísticos". A segunda chave estabelecida foi quanto ao tipo: "Jardim Histórico", reforçando a expressão humana individual ou coletiva da criação cultural, artística, e/ou ação projetiva sobre o meio.

A base conceitual para a elaboração da ficha de Cadastro Complementar, ou ficha especializada para caracterização dos Jardins Históricos, considerou o disposto na "Carta de Florença" (ICOMOS, 1982) e na "Carta de Juiz de Fora, dita Carta dos Jardins Históricos Brasileiros" (Iphan e gestores de jardins históricos, 2010). A primeira define Jardim Histórico como "uma composição arquitetônica e hortícola que apresenta interesse público do ponto de vista histórico ou artístico" e que, nesse sentido, "deve ser entendida como 'monumento"'. E complementa: "o jardim histórico é uma composição arquitetônica cujos constituintes são principalmente vegetais e, portanto, 

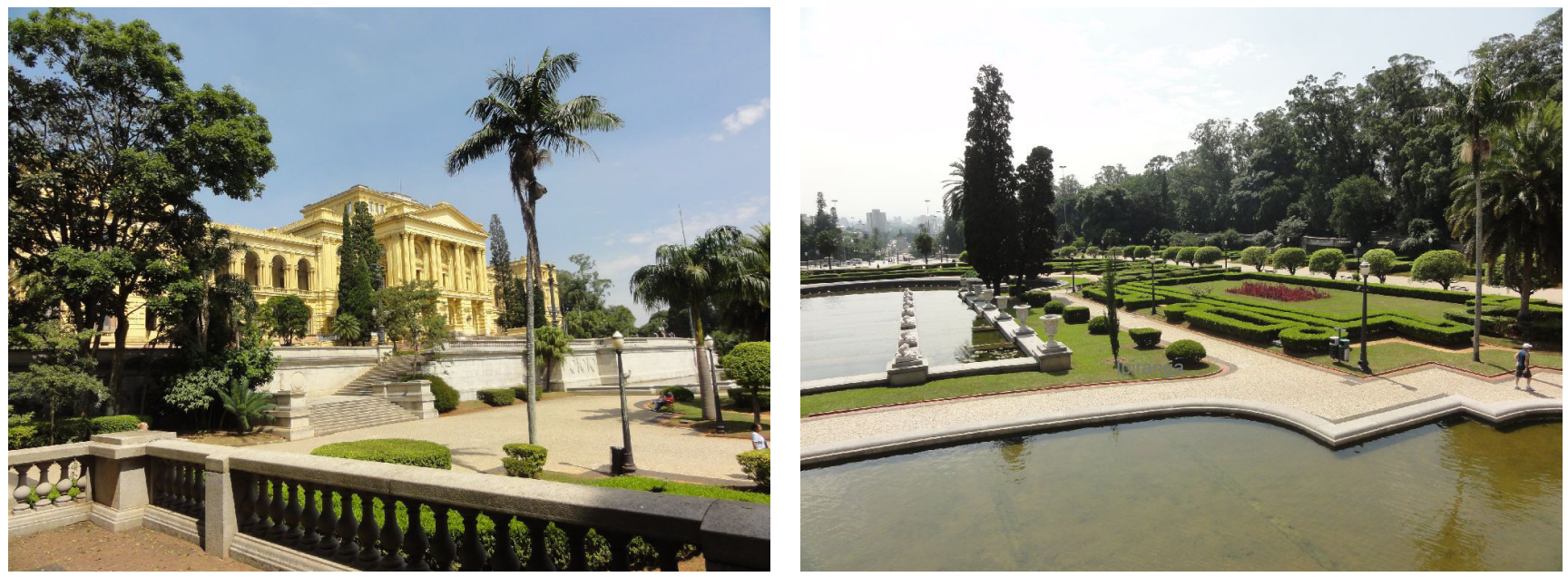

vivos, o que significa que são perecíveis e renováveis". Estabelece então que, na qualidade de 'monumento', o bem deve ser preservado de acordo com o espírito da Carta de Veneza; porém, por tratar-se de um 'monumento vivo', requer regras específicas de preservação, que são as explicitadas na referida Carta.

Já a Carta de Juiz de Fora, formulada por representantes do Iphan e seus parceiros gestores, considerou "Jardim Histórico" de maneira mais abrangente, para além da noção de "monumento" construído ou edificado pelo homem. De modo quase elástico, englobou também nesse conceito as paisagens e as várias formas de interação entre o homem e a natureza, considerando, ainda, o "espírito" dos lugares. Permitiu valorizar os jardins brasileiros comuns, entendidos como locais de encontro e de convívio social; os refúgios apaziguadores nas grandes metrópoles; os locais de relevância simbólica e afetiva; os jardins singelos e vernaculares da tradição brasileira; os jardins privados e suas composições florísticas; as hortas e pomares, entre vários outros. Buscava-se comunicar menos sobre a definição do termo em si e mais sobre a importância do reconhecimento dos valores culturais dos bens paisagísticos e do tratamento de suas especificidades, para saber preservá-los.

Enfim, partindo dessas duas bases (um tanto díspares quanto aos requisitos para patrimonialização e enquadramento dos bens paisagísticos); das experiências institucionais relacionadas aos jardins históricos; e das demandas advindas do próprio processo de
Jardins do Ipiranga/ Parque da Independência. Foto: MPS Associados, 2014. Fonte: Acervo IPHAN - "Inventário dos Jardins Históricos nas cidades do Rio de Janeiro/RJ e São Paulo/SP". Empresa contratada: MPS Associados Ltda (2014) 
constituição do SICG, foi proposto, no âmbito da Coordenação Geral de Patrimônio Natural - CGPN/Depam, a ficha de Cadastro Complementar dos Jardins Históricos.

Logo de início, conforme comentamos, a demanda foi por categorização dos bens, originando-se a classificação de "Bem Paisagístico", por sua vez, dividida em "Paisagem" ou “Jardim Histórico".

Quanto à ficha de "Jardim Histórico", objeto do presente artigo, a base de dados previu antes de tudo o quadro "Identificação", que é uma espécie de cabeçalho comum a todas as fichas do SICG. Na sequência, informações sobre o Recorte Territorial (identificação da região estudada); Recorte Temático (identificação do tema de estudo); Identificação do Bem (denominação oficial do bem, nome popular e outros); e o Código Identificador do Iphan (número criado como uma espécie de cédula de identidade do bem patrimonial).

Na sequência, está a delimitação do Jardim Histórico, com o georreferenciamento dos pontos de seu perímetro mais externo. Alimenta-se a base de dados com reunião de desenhos atuais, croquis e plantas de implantação, indicando-se, se possível, a apresentação da planta de piso e de cobertura vegetal, que podem ser elaboradas a partir de levantamento em campo e desenho sobre planta cadastral ou imagem do Google Earth. É salutar os referidos desenhos incluírem arruamentos e o que estiver no entorno imediato do bem, para situá-lo, especialmente se estiver contido em área urbana.

Ainda para complementar a visualização de imagens no cadastro do Jardim Histórico, são necessárias fotografias gerais e de detalhes do jardim, extraídas dos vários pontos de observação: do ambiente interno, do ambiente externo e desde locais mais altos nas proximidades, se houver.

São relevantes informações sobre o período de elaboração e construção do jardim, o ano de conclusão ou ano de inauguração. Em relação à tipologia, consideram-se o programa de atividades, a linguagem de desenho (partido arquitetônico adotado), composição formal, características estilísticas, datação. Da análise desses atributos, seleciona-se o tipo de Jardim Histórico entre: vernacular; romântico; clássico; moderno; ou contemporâneo.

Também a função principal do jardim deve ser demarcada, ou seja, a destinação para a qual o bem foi construído e que está correlacionada ao programa de necessidades: Jardim Botânico; Jardim Zoológico; Praça; Parque; Cemitério; Horta; Pomar; Largo e outros. 
Para correta caracterização de um jardim, é ainda fundamental observar sua origem: se por projeto formal, com autoria conhecida, ou se por criação anônima. Nesse caso, enquadramse também os jardins vernaculares e de criação coletiva. É importante que no cadastramento do bem sejam inseridas plantas ou imagens do projeto original, e que se faça uma breve descrição de sua fase mais antiga.

Paralelamente, revelem-se as intervenções no bem, especialmente quando se tratar de remodelações, alterações de projeto, com inserção e supressão de partes. Cada intervenção deve ser analisada detidamente, com informação sobre autoria, síntese descritiva e imagens, se houver.

Quanto aos elementos construídos do jardim, a base de dados prevê uma série de campos parametrizáveis (de se selecionar a opção desejada), permitindo precisão na busca, pesquisa e correlação das informações. Assim, resulta uma lista com os componentes construídos do jardim e comenta-se o estado de preservação e de conservação de cada parte, que por vezes difere do estado geral de preservação e de conservação do bem. Os elementos mencionados podem ser quantificados e foi previsto o campo "Observações" para relato, por exemplo, de elementos históricos ou correspondentes ao projeto original, frente a outros, contemporâneos ou de outras fases.

No item "Piso", pensado para calçada, calçadão, caminhos, deck e pavimentação, há a especificação dos materiais:

- Cimento: cimento queimado, cimentado, placa pré-moldada em concreto, piso intertravado, bloquete.

- Metal: aço corten, placa de aço, placa de aço pintada.

- Sintético: piso emborrachado, madeira sintética, grama sintética.

- Saibro: areia, pedrisco, seixo rolado, saibro (terra vermelha).

- Madeira: tábuas, tronco fatiado, dormente.

- Asfalto: asfalto, asfalto pigmentado.

- Pedra: mosaico português, basalto, granito, arenito, miracema, ardósia.

- Cerâmico: cerâmica queimada, tijolo, pastilha cerâmica de vidro.

- Outros.
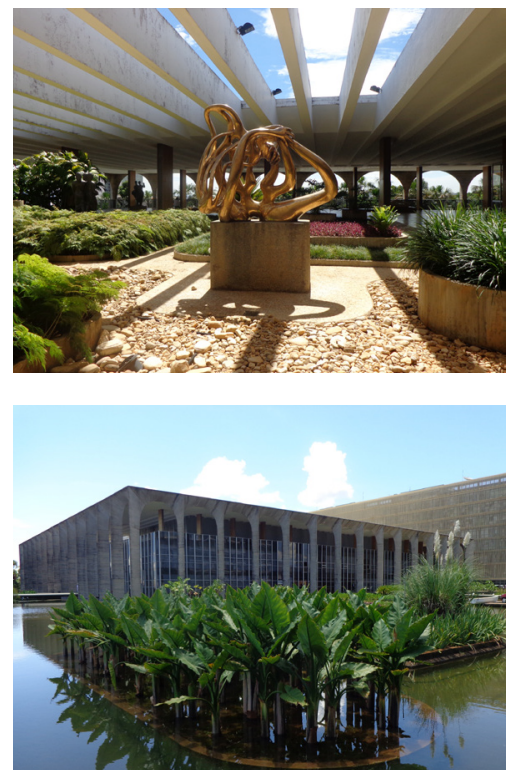

Ministério das Relações Exteriores - MRE/ Palácio do Itamaraty. Foto de Januaceli F. Murta, 2014 Fonte: Acervo IPHAN - "Inventário de conhecimento dos Jardins Históricos nas cidades de Brasília/ DF e Goiânia/GO". Empresa contratada: Memória Arquitetura Ltda (2014). 


\begin{tabular}{|c|c|}
\hline $\begin{array}{l}\text { No item "Arte no Espaço", podem-se } \\
\text { selecionar: }\end{array}$ & $\begin{array}{l}\text { No item "Banco", especificam-se } \\
\text { os materiais: }\end{array}$ \\
\hline - Escultura & - Madeira \\
\hline - Obelisco & - Sintético \\
\hline - Painéis & - Metal \\
\hline - Instalações & - Alvenaria \\
\hline - Outros & $\begin{array}{l}\text { - Concreto } \\
\text { - Misto }\end{array}$ \\
\hline $\begin{array}{l}\text { No item "Água": } \\
\text { - Cascata }\end{array}$ & - Outros \\
\hline - Espelho d'água & Em "Equipamentos de Lazer \\
\hline - Fonte & Esporte": \\
\hline - Equipamentos de água & - Campos de jogos \\
\hline - Chafariz & - Playground \\
\hline - Represa & - Quadra esportiva \\
\hline - Rio, riacho, lagoa & - Mesa de jogos \\
\hline - Outros & - Pista de skate/Patins \\
\hline & - Esporte aquático \\
\hline & - Equipamentos de ginástica \\
\hline & - Piquenique ou churrasqueira \\
\hline & - Piscina \\
\hline & - Outros \\
\hline
\end{tabular}




\begin{tabular}{|c|c|}
\hline $\begin{array}{l}\text { Em "Acessibilidade" - elementos } \\
\text { integrados no jardim: }\end{array}$ & $\begin{array}{l}\text { - Canalização da água } \\
\text { - Tratamento de água e esgoto }\end{array}$ \\
\hline - Ciclovia & - Subestação elétrica \\
\hline - Rampa & - Sistema de irrigação \\
\hline - Piso podotátil & - Torre de transmissão \\
\hline - Elevador & - Outros \\
\hline - Teleférico & \\
\hline - Piso indicativo & Em "lluminação" - suporte: \\
\hline - Estacionamento & - Poste alto \\
\hline - Mini-carro & - Balizador \\
\hline - Rampa de acesso & - Poste baixo \\
\hline - Transporte público & - Refletor \\
\hline - Passarela de pedestre & - Spot \\
\hline - Heliporto & -Outros \\
\hline - Píer de Atracação & \\
\hline - Outros & $\begin{array}{l}\text { Em "Iluminação" - tipos de lâmpadas: } \\
\text { - LED }\end{array}$ \\
\hline Em "Infraestrutura": & - Fluorescente \\
\hline $\begin{array}{l}\text { - Equipamentos para controle } \\
\text { de inundação }\end{array}$ & - Vapor de sódio \\
\hline - Gerador & - Subaquáticas \\
\hline - Sistema de drenagem & - Incandescente \\
\hline - Painel fotovoltaico & $\begin{array}{l}\text { - Vapor metálico } \\
\text { - Outros }\end{array}$ \\
\hline
\end{tabular}




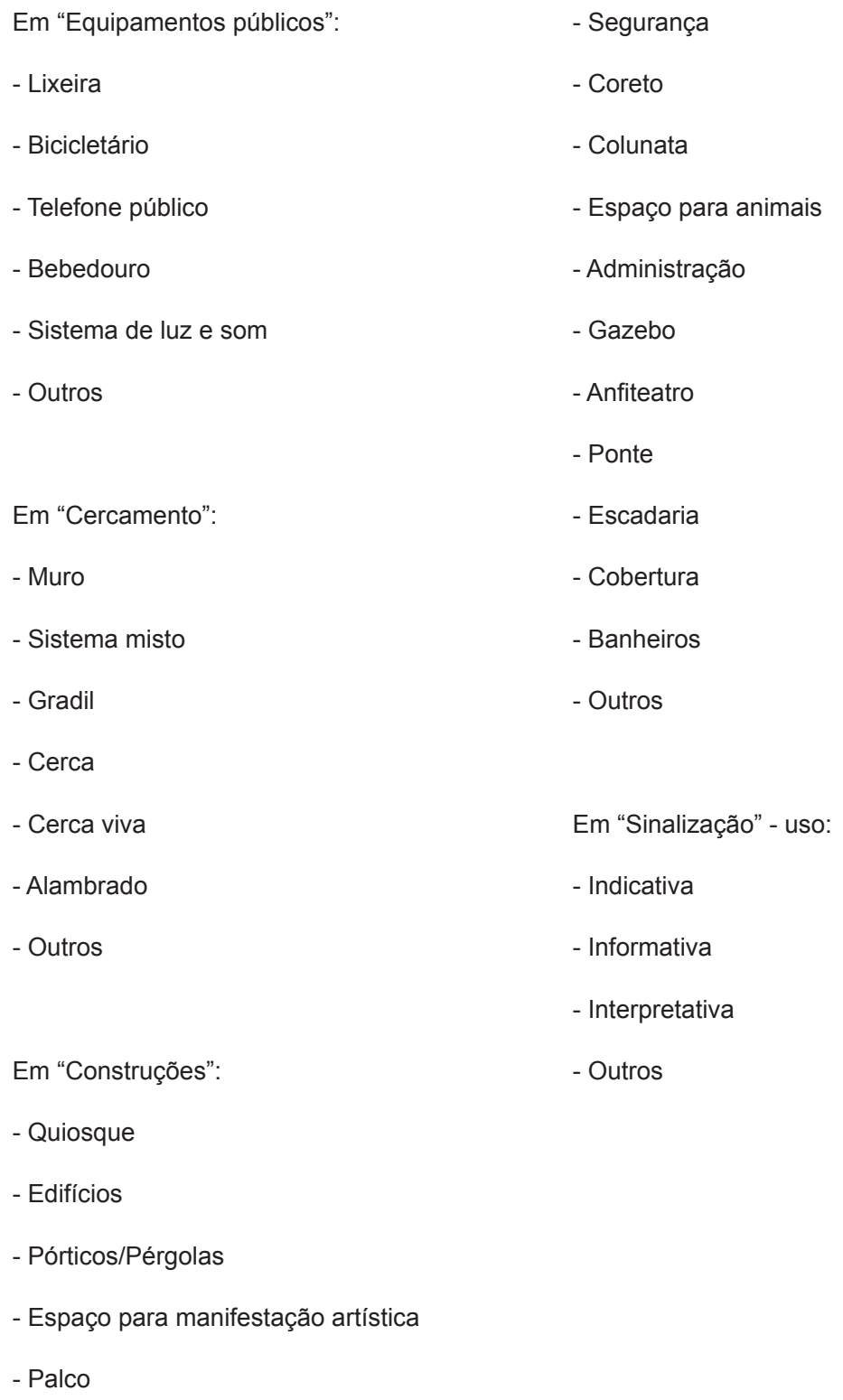




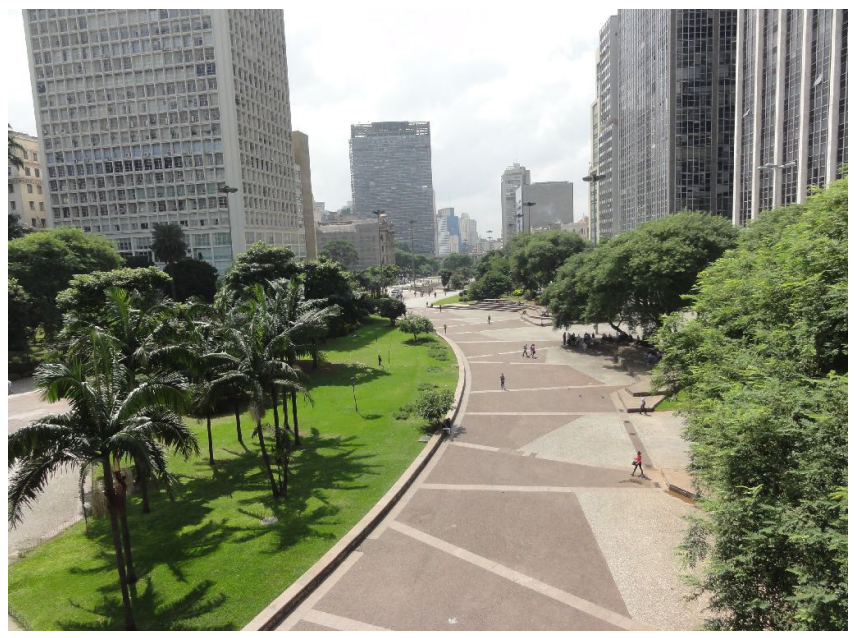

Caracterizada a parte construída do jardim, passa-se à apreciação dos elementos florísticos. Para isso, faz-se uma descrição geral da vegetação no jardim, incluindo observação sobre as massas vegetadas e sobre a localização das principais espécies, que podem constar em uma implantação, imagem ou no próprio mapeamento florístico.

Em seguida, deve ser preenchida uma tabela contendo: estrato, nome popular, nome científico, família botânica, quantidade de espécimes. Nos casos de jardim muito extenso, em que o levantamento florístico for impossibilitado, basta quantificar espécies arbóreas e palmeiras, identificando as massas vegetais.

Procede-se, então, à análise de preservação e conservação dos elementos florísticos, sendo que o primeiro diz respeito à sua correspondência em relação ao projeto original; o segundo incorre em análise fitossanitária, que pode envolver espécies ou indivíduos.

O quadro seguinte é o do uso atual do jardim, devendo-se descrever a frequência e as atividades realizadas durante as estações do ano, períodos do dia e da noite, podendo-se detalhar o público usuário e sua apropriação do local.

Aprofundando as análises quanto às tradições e apropriação simbólica, importa considerar as relações estabelecidas entre as comunidades vizinhas e o bem, buscando a compreensão dos significados atribuídos ao local. Cabem observações sobre o gerenciamento do local, se
Vale do Anhangabaú. Foto: MPS Associados, 2014. Fonte: Acervo IPHAN - "Inventário dos Jardins Históricos nas cidades do Rio de Janeiro/RJ e São Paulo/SP". Empresa contratada: MPS Associados Ltda (2014) 

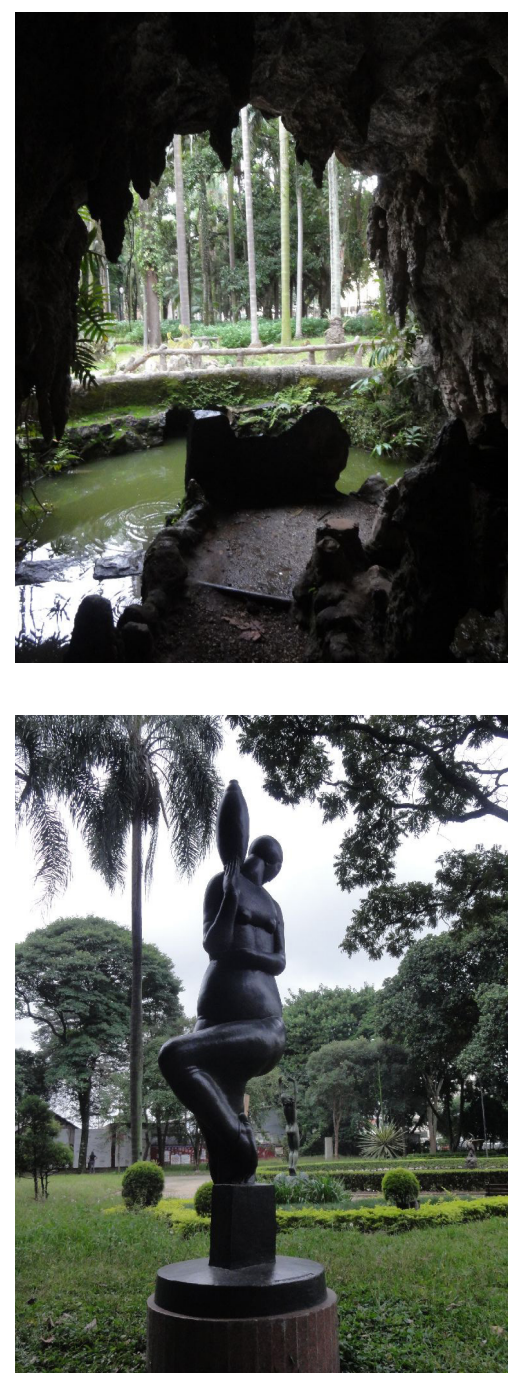

Parque da Luz Parque da Luz. Foto: MPS Associados, 2014. Fonte: Acervo IPHAN - "Inventário dos Jardins Históricos nas cidades do Rio de Janeiro/RJ e São Paulo/SP". Empresa contratada: MPS Associados Ltda (2014) as comunidades auxiliam nos cuidados do bem, se há realização de festas, manifestações e eventos, entre outros.

Em relação aos fatores de risco e vulnerabilidade, requerem-se informações sobre o que impacta negativamente o bem e sobre possíveis causas da vulnerabilidade do jardim (fatores antrópicos, fatores naturais, falta de vigilância etc).

Por fim, devem ser descritas as relações entre o bem e seu entorno, chamando a atenção se há integração entre eles ou se, ao contrário, o jardim acha-se isolado do contexto urbano, por mudanças operadas. Cabe ainda assinalar se há afinidade, em termos formais, entre o jardim e a arquitetura dos edifícios que o circundam.

Com isso, encerra-se a ficha de Cadastro Complementar dos Jardins Históricos, incluindo informações sobre as fontes bibliográficas e documentais utilizadas, e a identificação do responsável pelo preenchimento.

\section{INVENTÁRIOS DE JARDINS HISTÓRICOS REALIZADOS}

Concebidas as fichas SICG para os Jardins Históricos, O IPHAN tratou de colocá-las em prática e em teste de aplicação. Com essa finalidade, foi aprovada a contratação de serviços técnicos especializados para realizar os Inventários de Jardins Históricos em cidades determinadas. Selecionaram-se duas equipes multidisciplinares integradas por profissionais de nível superior com experiência em paisagismo, botânica e em realização de pesquisa.

Pretendeu-se a geração de conhecimento sistematizado sobre jardins brasileiros, tendo em vista que esse tipo de bem patrimonial é pouco estudado, divulgado ou protegido (exceção feita àqueles que se destacam pela excepcionalidade). A ação centrou-se em incrementar os subsídios técnicos para os processos institucionais de proteção, difusão e gestão dessa categoria de bem.

Isso foi feito considerando-se a disponibilidade de numerosos trabalhos produzidos sobre Paisagismo Brasileiro em universidades, grupos de pesquisa e entre profissionais especializados no tema. As investigações contemplaram, também, Bancos de Dados virtuais de instituições, entidades ou órgãos públicos, nacionais e/ou internacionais, que tratam de jardins históricos. 

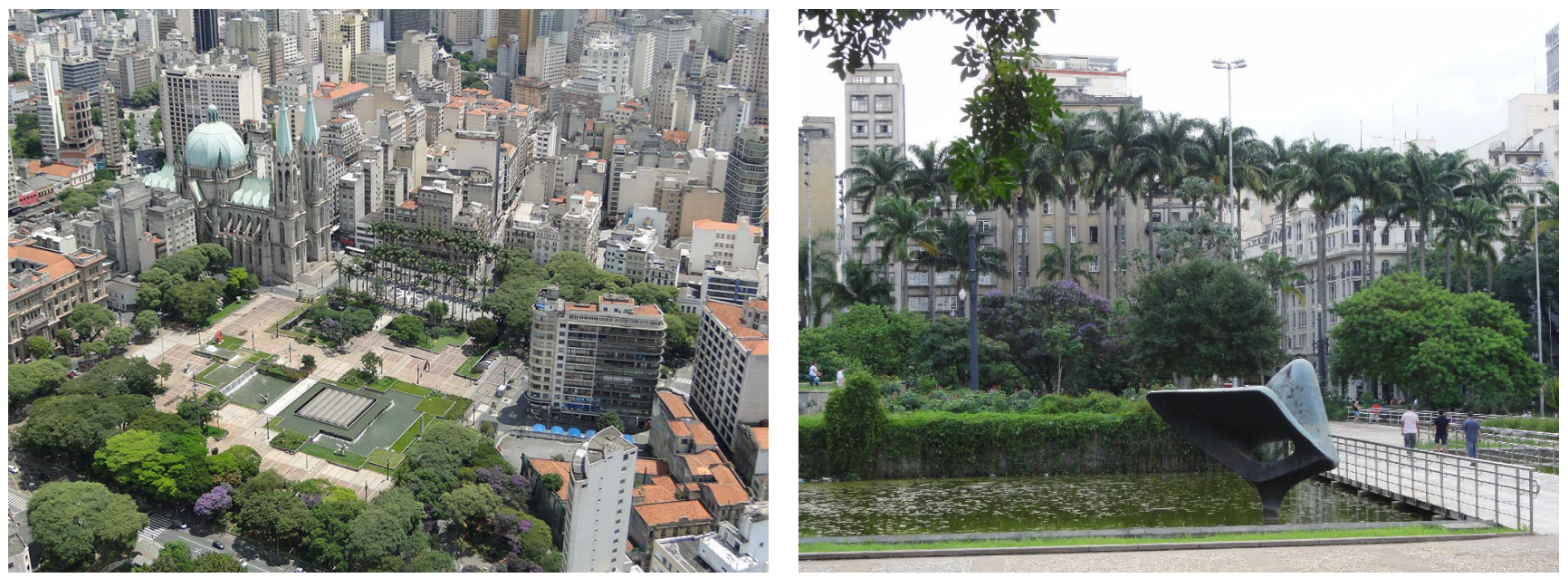

Foi demandado às equipes o preenchimento das fichas M101 para um panorama geral sobre os jardins no Brasil, e das mesmas M101 para contextos regionais, sendo que um trabalho enfocou jardins históricos nos grandes centros urbanos do Sudeste - Eixo Rio-São Paulo, e o outro, os jardins nas cidades planejadas do Centro-Oeste - Brasília e Goiânia, bem como seu papel na constituição e evolução dessas cidades.

Para o conhecimento ampliado dos jardins, foi necessário considerar, conforme cada caso, sua gênese, características estilísticas, filiações, usos cotidianos, funções, apropriação simbólica, evolução e transformações até a atualidade.

No Rio de Janeiro, os jardins selecionados para o preenchimento das fichas M300, M301 e M308 foram: Passeio Público, Campo de Santana, Jardins do Palácio Gustavo Capanema, Jardins da Casa de Rui Barbosa, Jardins do Palácio do Catete, e Parque da Península (antiga Gleba E). Em São Paulo: os do Trianon, da Luz, Vale do Anhangabaú, Museu da Independência, Parque da Juventude e Praça da Sé.

Como resultado da pesquisa sobre as grandes cidades do Sudeste, foram feitas análises quanto à "preparação das centralidades para o fenômeno da metropolização" e sobre o desenho dos espaços livres públicos (e privados) no território das cidades. Constatou-se que, diante de acelerados processos de transformação da malha urbana, e das muitas
Praça da Sé. Foto: MPS Associados, 2014. Fonte: Acervo IPHAN - "Inventário dos Jardins Históricos nas cidades do Rio de Janeiro/RJ e São Paulo/SP". Empresa contratada: MPS Associados Ltda (2014) 
Praça dos Cristais/ Setor Militar Urbano - SMU. Foto de Januaceli F. Murta, 2014. Fonte: Acervo IPHAN "Inventário de conhecimento dos Jardins Históricos nas cidades de Brasília/DF e Goiânia/GO". Empresa contratada: Memória Arquitetura Ltda (2014).

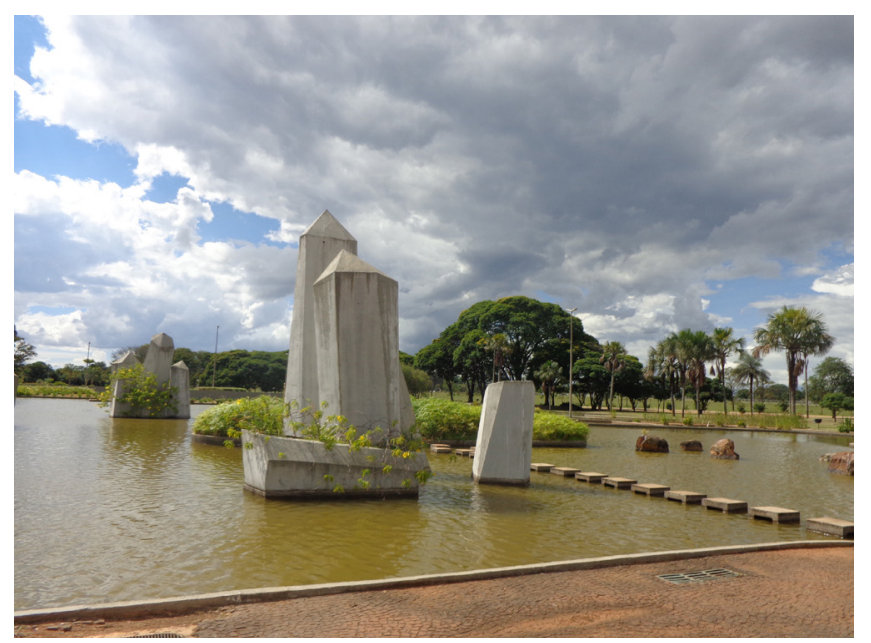

fases da urbanização, os jardins históricos auxiliam a compreensão do tecido urbano e testemunham no processo de acumulação de diferentes tempos. Ainda que a fisionomia original do território sempre se altere ou se apague, os jardins históricos sobrevivem nesse processo; daí a importância de sua continuada ativação em relação a espaços contemporâneos.

Essa permanência explica-se pelo esforço de valorização dos espaços públicos centrais e porque alguns jardins adquiriram, ao longo de sua história, status de lugar público referencial. Eles promovem experiências diferenciadas, ancoradas na proximidade com a natureza, na função de recreação, lazer, oportunidade de convívio e respiro bem-vindo entre a massa edificada.

Além disso, os jardins históricos selecionados para cadastramento são ilustrativos de diferentes concepções projetuais, quanto à expressão histórica e artística, e quanto à base conceitual adotada. Demonstram linhas de renovação no paisagismo e também os processos de contato entre diferentes culturas, pois variam entre elaborados por engenheiros e paisagistas do exterior, e projetados por técnicos e artistas brasileiros envolvidos no desenvolvimento dos planos e projetos de urbanização.

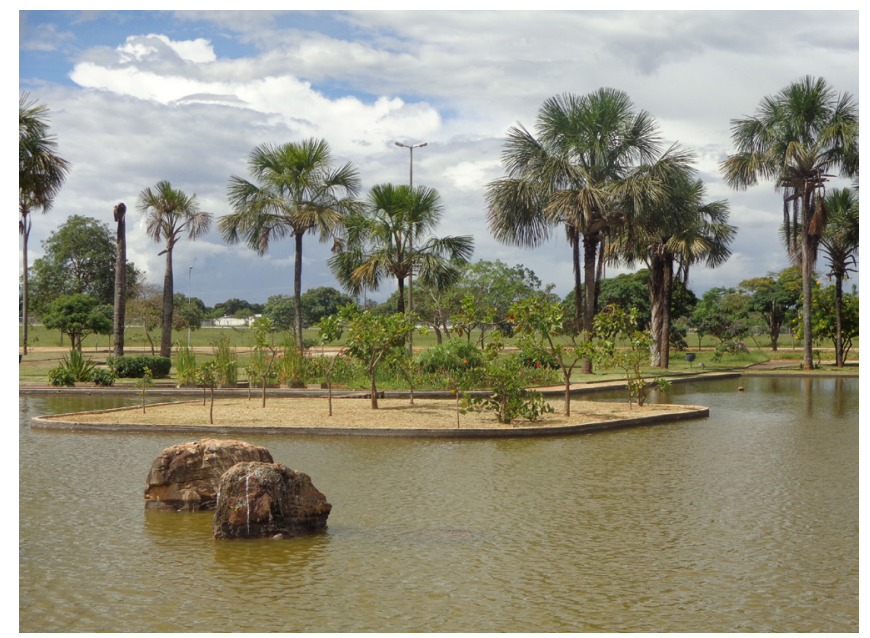


Por sua vez, o inventário que tratou dos jardins históricos nas cidades planejadas do Centro-Oeste enfatizou o esforço de colonização dos "vazios territoriais" no interior do país, empreendido entre as décadas de 1930 e 1970. "Nestas novas cidades, a dimensão simbólica afirmava uma determinada 'modernidade' brasileira expressa na arquitetura e na concepção urbanística que conjugava áreas construídas com projetos de arborização e ajardinamento". (IPHAN/ Memória Arquitetura Ltda, 2014).

Goiânia foi projetada e construída em 1930, enquanto Brasília foi inaugurada em 1960. "Cidades administrativas e capitais, foram ambas construídas por deliberação do poder público, diretamente associadas seja a políticas gerais de colonização das fronteiras agrícolas, ou de expansão para fins geopolíticos, no bojo das políticas desenvolvimentistas alimentadas por ideologias do progresso e civilizatórias". (IPHAN/ Memória Arquitetura Ltda, 2014).

Essas cidades foram valorizadas como o início da "Marcha para o Oeste" brasileira, que levaria ao reconhecimento de si por parte do país e, com isso, ao progresso com base na realidade da nação. O processo culminaria com a transferência da Capital Federal para o centro do território do país.

Assim, "ambas as cidades possuem características semelhantes no que se refere às determinações simbólicas de seus traçados. O que Ihes atribui significado político específico, distinguindo-as de outras cidades novas, é sobretudo o desenho de seus centros cívicos. A estes é conferida uma forte monumentalidade, seja através da arquitetura dos edifícios públicos que vão se distribuir ao longo ou em torno de praças e grandes eixos, ou por meio da forma de seus espaços públicos e abertos, seus jardins, com um desenho geometrizado, regular e simétrico, quase barroco, com o emprego de vias estruturais ou diagonais, 'pattésd'oie' e praças estelares". (IPHAN/ Memória Arquitetura Ltda, 2014).

Nesse contexto, os jardins inventariados foram, em Goiânia/GO: a Praça Cívica, os Jardins da Avenida Goiás, o Lago das Rosas, a Praça Universitária, a Praça do Avião (Setor Aeroporto) e o Bosque dos Buritis.

Em Brasília/DF: a Praça dos Cristais, o Parque Olhos d'Água, os Jardins da Superquadra Sul 308, os Jardins da Superquadra Sul 714, os Jardins do Palácio do Itamaraty e o Parque da Cidade Sarah Kubitschek. 
Ainda segundo a contratada, "somente a partir da década de 1920, os modelos europeus de constituição de parques e jardins passaram a sofrer críticas no Brasil. Tiveram participação na superação dos modelos europeus ligados ao Neoclassicismo os intelectuais e artistas modernistas brasileiros, que redimensionaram as relações entre tradição e modernidade, afirmando a existência de um 'sentimento nacional', de uma 'realidade nacional' que poderia ser expressa nas mais diversas formas de arte. O paisagismo de Roberto Burle Marx, neste sentido, apresentou uma nova forma de lidar com as espécies vegetais e de sua articulação com o ambiente construído na composição das paisagens. O paisagismo de Roberto Burle Marx alinhava-se com a corrente arquitetônica/urbanística moderna, cujos principais expoentes foram Lúcio Costa e Oscar Niemeyer. Juntos, eles foram responsáveis pela internacionalização de uma forma brasileira de tratar os problemas da arquitetura, das cidades e da relação entre natureza e ambiente construído que tinha influência da teoria das 'cidades-jardim' europeias e dos CIAM - Congressos Internacionais de Arquitetura Moderna, que propunham um sistema de ocupação do solo que mesclasse os elementos benéficos dos aspectos naturais e artificiais, equacionando os dois no planejamento das cidades visando à qualidade de vida das populações". (IPHAN/ Memória Arquitetura Ltda, 2014).

Esses estudos de inventários, muito ricos em conteúdo, e cada qual disponível em volumes impressos e acompanhados dos respectivos CD's, estão disponíveis para consulta nas Superintendências do IPHAN envolvidas, e na própria área central, DEPAM, em Brasília, uma vez que o SICG como sistema informatizado ainda está em fase de implantação e homologação.

Parque da Juventude. Foto: MPS Associados, 2014 Fonte: Acervo IPHAN - "Inventário dos Jardins Históricos nas cidades do Rio de Janeiro/RJ e São Paulo/SP". Empresa contratada: MPS Associados Ltda (2014)

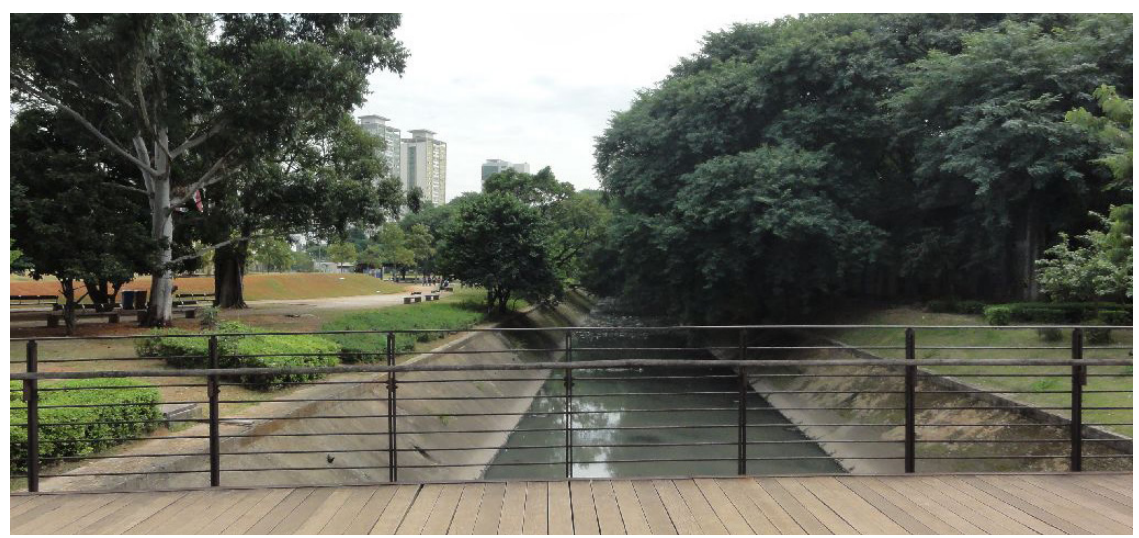


ID_PESQUISAS

\section{CONCLUSÃO}

O que se buscou retratar nesse artigo foram visões sobre jardins históricos e paisagens debatidas no IPHAN, tanto durante a elaboração do SICG e concepção de suas fichas específicas, quanto por ocasião da contratação de pessoal especializado que pesquisou sobre jardins históricos significativos nas cidades brasileiras.

Em breve, esse conhecimento produzido deverá estar disponível online para a sociedade, que deve se tornar cada vez mais parceira nos trabalhos de preservação. 
ID_PESQUISAS

\section{REFERÊNCIAS BIBLIOGRÁFICAS}

Acervo IPHAN (2009). "Manual de Aplicação do Sistema Integrado de Conhecimento e Gestão - SICG". Brasília.

Acervo IPHAN (2009). "Plano Estratégico de revisão dos inventários - proposta preliminar. Inventários, informação, gestão". Documento interno.

Acervo IPHAN (2014). "Inventário dos Jardins Históricos nas cidades do Rio de Janeiro/RJ e São Paulo/ SP”. Empresa contratada: MPS Associados Ltdal.

Acervo IPHAN (2014). "Inventário de conhecimento dos Jardins Históricos nas cidades de Brasillia/DF e Goiânia/GO”. Empresa contratada: Memória Arquitetura Ltda. 